\title{
HAKIKAT BUDAYA JAWA KAITANNYA DENGAN AGAMA HINDU DI BALI
}

\author{
Oleh: Poniman
}

Dosen Fakultas Brahma Widya IHDN Denpasar

\begin{abstract}
Abstrak
Keberadaan budaya Bali telah berlangsung dengan adanya pengaruh asing. Demikian pula ketika Agama Hindu dan Buddha dianut oleh masyarakat Bali. Hal itu juga mempengaruhi Agama Hindu di Bali yang sampai saat ini terlihat dominan dan memberi rona serta mewarnai budaya dan kehidupan masyarakat Bali. Sampai saat ini, keberadaan Agama dan Budaya Bali menghadapi tantangan global, tantangan materialisme, dan bahkan dampak perkembangan Media Sosial mempengaruhi kebudayaan Bali. Mengetahui Hakikat Budaya Jawa dalam kaitanya dengan perkembangan Hindu di Bali membentuk karakter Hindu Bali yang pada akhirnya menjadi Budaya Bali. Agama Hindu di Bali lebih terlihat pada Adat dan Tradisinya, hal ini diakibatkan adanya pembudiyaan Agama menjadi praktik kehidupan nyata. Sehingga keberadaan Agama Hindu tidak secara jelas terlihat dengan kitab Wedanya sebagai dasar pedomannya melainkan Lontar-Lontar yang dijadikan praktik dalam adat baik dalam ritual maupun nyastra sehingga tidak dijumpai ketika acara keagamaan memakai Weda sebagai bahan bacaan di Pura maupun dalam pedoman ritualnya.

Kata Kunci : Budaya, agama Hindu
\end{abstract}

\section{Abstract}

The existence of Balinese culture has taken place in the presence of foreign influences. Similarly, when Hinduism and Buddhism were embraced by Balinese people. It also affects Hinduism in Bali, which until now seems dominant and gives a hue and coloring the culture and life of Balinese people. Until now, the existence of the Religion and Culture of Bali faced global challenges, the challenges of materialism, and even the impact of the development of Social Media influenced Balinese culture. Knowing the Nature of Javanese Culture in relation to the development of Hinduism in Bali forms the character of Balinese Hinduism which eventually becomes the Balinese Culture. Hinduism in Bali is more visible in Adat and Tradition, this is due to the formation of Religion as a real-life practice. So that the existence of Hinduism is not clearly seen with the Wedanya book as the guiding basis but Lontar-Lontar which is used as a practice in adat both in rituals and literature so it is not found when religious events use Vedas as reading material in Pura and in ritual guidelines.

Keywords: Culture, Hinduism

\section{A.Pendahuluan}

Sudah menjadi bahan perbincangan yang panjang, ketika perkembangan umat Hindu di Jawa saat ini dipengaruhi oleh masuknya Budaya
Bali. Demikian jika disimak ketika suatu postingan di media sosial. Namun demikian tidak banyak yang memperbincangkan ketika sesungguhnya keberadaan Budaya Bali banyak dipengaruhi oleh Budaya Jawa. Maka melalui tulisan ini 
sedikit akan menggugah serta mengingatkan bahwa munculnya peradaban manusia itu selalu mengalami perubahan yang didalamnya banyak terdapat sumber yang mempengaruhinya sehingga terbentuknya suatu Budaya. Demikian Budaya yang diciptakan manusia akan selalu mengalami perubahan seiring perkembangan jamannya.

Keberadaan Agama Hindu di Bali dan Budaya Bali terlihat memiliki perpaduan tampak sejak masa prasejarah Bali. Dari tinggalan arkeologi ditemukan bahwa Bali telah mengadakan hubungan dengan India, China dan Jawa. Keberadaan budaya Bali telah berlangsung dengan adanya pengaruh asing. Demikian pula ketika Agama Hindu dan Buddha dianut oleh masyarakat Bali. Hal itu juga mempengaruhi Agama Hindu di Bali yang sampai saat ini terlihat dominan dan memberi rona serta mewarnai budaya dan kehidupan masyarakat Bali. Walaupun demikian, kedatangan dan pengaruh Agama Buddha, Kong $\mathrm{Hu} \mathrm{Chu}$, Tao juga kepercayaan masa prasejarah bersinergi dengan pertumbuhan budaya Bali. Sejak keruntuhan Majapahit di Jawa Timur, Bali mampu mempertahankan identitas budayanya. Pengaruh Islam turut pula memberi warna dalam perkembangan kebudayaan Bali. Pada masa penjajahan Belanda, para misionaris Kristen (Katolik dan Protestan) juga mengembangkan sayapnya di Bali yang berlanjut dengan pergerakkan kebangsaan, yang kemudian diikuti dengan tumbuh dan berkembang nasionalisme Indonesia. Sejalan dengan hal tersebut Bali semakin mampu menunjukkan jati dirinya dan budaya Bali mulai tampil di berbagai belahan dunia seperti telah dijelaskan di atas.

Sampai saat ini, keberadaan Agama dan Budaya Bali menghadapi tantangan global, tantangan materialisme, dan bahkan dampak perkembangan Media Sosial mempengaruhi kebudayaan Bali. Bagaimana Hakikat Budaya Jawa kaitannya dengan Agama Hindu Bali yang membentuk Budaya Bali tersebut akan dibahas dalam tulisan ini.

\section{B. Hakikat Budaya Jawa}

Mulanyadiceritakan dalam berbagai tulisan bahwa Pulau Jawa seolah terbungkus oleh misteri, karena sama sekali tidak diketahui keberadaannya oleh dunia sampai pulau ini dikunjungi oleh peziarah dari China, Fa Hien pada tahun 412 Masehi. Namun berdasarkan buku Sejarah Gaib Tanah Jawa, karangan CW Leadbeater, Cetakan 1 Maret 2015, disebutkan, pada 2.000 tahun sebelum masehi (SM), dan dikatakan bahwa keberadaan Pulau Jawa sudah menjadi koloni bangsa Atlantis, akan tetapi saat Atlantis mengalami kehancuran, Pulau Jawa menjadi suatu negeri terpisah antara berbagai pulau lainnya.

Sejak jaman kerajaan hingga saat ini keberadaan Pulau Jawa adalah pulau yang menjadi aikon disamping pulau lainnya di Nusantara. Hal itu beralasan sebab di pulau ini pusat administrasi pemerintahan Indonesia di jalanan. Oleh karenanya pulau ini menjadi pualu terpadat di Indonesia. Sebelum islam masuk di pulau jawa terlebih dahulu agama hindu budha masuk dan menjadi agama yang di ikuti masyarakat jawa.

Pada perkembangannya terjadilah akulturasi Budaya Jawa dan Agama Hindu-Budha yang di bawa para pedagang dan biksu dari India, menghasilkan budaya yang baru. Apalagi setelah adanya pengaruh Islam masuk di Jawa yang di bawa para pedagang dan para wali, budaya di jawa semakin ter akulturasi dari islam dan agama Hindu Budha. Oleh karena itu sesungguhnya Budaya Jawa merupakan Akulturasi dari Budaya Hindu-Buddha dan Islam yang datang ketika masa kerajaan yang hingga saat ini masih menjadi perdebatan Identitasnya. Lalu bagaimana dengan kebradaan Agama Hindu di Bali, berikut akan dipaparkan agar dapat memberikan benang merah dalam menyikapi keberadaan Agama Hindu dan Budaya Bali yang sampai kini juga menjadi bahan perdebatan intelektual dalam khasanah identitasnya. 


\section{Hakikat Agama Hindu di Bali}

Untuk memahami keberadaan Agama Hindu yang berkembang di Bali, maka perlu dipahami dasar disebutnya sebagai Agama Hindu bahwa tidak lepas dari Kitab Suci Weda sebagai pedoman keberagamaannya. Selain kitab suci Veda (Úruti) yakni wahyu Tuhan Yang Maha Esa sebagai sumber tertinggi, dikenal pula hiarki sumber ajaran Agama Hindu yang lain yang merupakan sumber hukum Hindu adalah Småpi (kitab-kitab Dharmaúàstra atau kitab-kitab hukum Hindu), Úìla (yakni tauladan pada mahàrûi yang termuat dalam berbagai kitab Itihàsa (sejarah) dan Puràóa (sejarah kuno), Àcàra (tradisi yang hidup pada masa yang lalu yang juga dimuat dalam berbagai kitab Itihàsa (sejarah) dan Àtmanaûtuûpi, yakni kesepakatan bersama berdasarkan pertimbangan yang matang dari para mahàrûi dan orang-orang bijak yang dewasa ini diwakili oleh majelis tertinggi umat Hindu dan di Indonesia disebut Parisada Hindu Dharma Indonesia Pusat yang dipresentasikan dengan kedudukan Sabha Pandita sebagai organ tertinggi Parisada, sedang Pengurus Harian adalah sebagai eksekutan yang bila melanggar AD/ART dapat diberhentikan oleh Sabha Pandita. Majelis yang dipresentasikan oleh Sabha Pandita inilah yang berhak mengeluarkan Bhîuama (semacam fatwa) bilamana tidak ditemukan sumber atau penjelasannya di dalam sumber-sumber ajaran Hindu yang kedudukannya lebih tinggi.

Keberadaan Hindu Dharma yang berkembang di Bali memperkenalkan kemerdekaan mutlak terhadap pikiran rasional manusia. Hindu Dharma tidak pernah menuntut sesuatu pengekangan yang tidak semestinya terhadap kemerdekaan dari kemampuan berpikir, kemerdekaan dari pemikiran, perasaan dan pemikiran manusia. Ia memperkenalkan kebebasan yang paling luas dalam masalah keyakinan dan pemujaan. Hindu Dharma adalah suatu agama pembebasan. Ia memperkenalkan kebebasan mutlak terhadap kemampuan berpikir dan perasaan manusia dengan memandang pertanyaan-pertanyaan yang mendalam terhadap hakekat Tuhan Yang Maha Esa, jiwa, penciptaan, bentuk pemujaan dan tujuan kehidupan ini. Hindu Dharma tidak bersandar pada satu doktrin tertentu ataupun ketaatan akan beberapa macam ritual tertentu maupun dogma-dogma atau bentuk-bentuk pemujaan tertentu. Ia memperkenalkan kepada setiap orang untuk merenungkan, menyelidiki, mencari dan memikirkannya, oleh karena itu, segala macam keyakinan/Úraddhà, bermacam-macam bentuk pemujaan atau Sàdhana, bermacam-macam ritual serta adat-istiadat yang berbeda, memperoleh tempat yang terhormat secara berdampingan dalam Hindu Dharma dan dibudayakan serta dikembangkan dalam hubungan yang selaras antara yang satu dengan yang lainnya.

Tafsiran terhadap Hindu Dharma di dalam Mahàbhàrata dapat dijumpai sebuah pernyataan : "Bukanlah seorang mahàrûi (muni) bila tidak memberikan pendapat terhadap apa yang dipahami" (Radhakrishnan, 1989: 27). Inilah salah satu ciri atau karakteristik dari Hindu Dharma. Karakteristik atau ciri khas lainnya yang merupakan barikade untuk mencegah berbagai pandangan yang memungkinkan tidak menimbulkan pertentangan di dalam Hindu Dharma adalah Adikàra dan Î́pa atau Iûpadevatà. Adikàra berarti kebebasaan untuk memilih disiplin atau cara tertentu yang sesuai dengan kemampuan dan kesenangannya, sedangkan Iûpa atau Iûpadevatà adalah kebebasan untuk memilih bentuk Tuhan Yang Maha Esa yang dijelaskan daalam kitab suci dan susatra Hindu, yang ingin dipuja sesuai dengan kemantapan hati.

Svami Sivananda, seorang dokter bedah yang pernah praktek di Malaya (kini Malaysia) kemudian meninggalkan profesinya itu menjadi seorang Yogi besar dan rohaniawan agung pendiri Divine Life Society menyatakan: Hindu Dharma sangatlah universal, bebas, toleran dan luwes. Inilah gambaran indah tentang Hindu Dharma. Seorang asing merasa terpesona keheranan apabila mendengar tentang sekta-sekta dan keyakinan 
yang berbeda -beda dalam Hindu Dharma; tetapi perbedaan-perbedaan itu sesungguhnya merupakan berbagai tipe pemahaman dan tempramen, sehingga menjadi keyakinan yang bermacam-macam pula. Hal ini adalah wajar. Hal ini merupakan ajaran yang utama dari Hindu Dharma; karena dalam Hindu dharma tersedia tempat bagi semua tipe pemikiran dari yang tertinggi sampai yang terendah, demi untuk pertumbuhan dan evolusi mereka (Sivananda, 1988: 134).

Karakteristik Ajaran Hindu Dharma sebagai telah diuraikan di atas, tidaklah berarti ajaran Agama Hindu itu tidak jelas dan menafsirkannya di luar kewenangan dan jangkauan kitab suci. Untuk itu pada masa berdirinya kerajaan di Jawa disalinlah tulisan-tulisan dari Kitab Suci dari Bahasa Sansekerta kedalam bahasa Jawa Kuno. Hal ini guna mempermudah dalam mempelajarinya dan bukti itu bisa kita jumpai sampai saat ini di Bali adanya teks-teks suci yang tertulis dalam Lontar-Lontar baik yang diarsipkan di Pusat Dokumentasi daerah maupun di berbagai tempat lainnya di Bali. Tulisan dalam lontar memakai aksara Jawa dan berbahasa saksekerta serta Jawa-Kuno. Tidak dijumpai adanya tulisan kuno yang memakai bahasa daerah Bali hal ini menunjukkan bahwa sesungguhnya Teks-teks dalam Lontar di Bali merupakan karya dari Jawa yang disebarluaskan sampai ke Bali.

Demikian banyaknya variasi di dalam Hindu Dharma, namun sesungguhnya ajarannya dimanamana dan kapan saja sama. Essensi ajaran Hindu Dharma yang bersumber dan mengalir dari kitab suci Veda dengan susatra Hindu lainya yang ditulis dalam berbagai bahasa dirumuskan dalam ajaran Úraddhà (Tattva) atau keimanan, dilaksanakan dan diejawantahkan dalam prilaku Tata Suúila atau budi pekerti berdasarkan ajaran Dharma dan ekspresinya nampak pada dalam Àcàra Agama.

Ajaran Úraddhà yang merupakan dasar keimanan Hindu Dharma di Bali dirumuskan dalam Pañca Úraddhà, yakni keyakinan terhadap
Brahman, para dewa manifestasi-Nya dan AvataraNya, keyakinan terhadap kebenaran Atman, roh atau jiva yang menghidupkan semua mahluk dan Atman merupakan percikan-Nya (Brahman/Tuhan Yang Maha Esa) Yang Trancendent maupun Yang Immanet. Úraddhà, keyakinan atau keimanan yang ketiga adalah terhadap kebenaran adanya Karmaphala (hukum perbuatan), keimanan yang keempat adalah keyakinan terhadap penjelmaan kembali, Samsara (rebith) dan yang kelima adalah Mokûa, yakni kebebasan tertinggi yang mesti dicapai umat manusia, bersatunya Atman dengan Brahman, Tuhan Yang Maha Esa.

Keanekaragaman yang ada terlihat dalam bentuk luarnya, namun memiliki satu keragaman dan satu tujuan mewujudkan kesejahtraan jasmani dan rohani serta bersatunya Àtman dengan Brahman. Kalimat ini kemudian diformulasikan dan dijadikan motto oleh Sri Ramakrishna Mission, sebagai berikut.

\section{"Àtmanaá Mokûàrthaý Jagadhitàya ca"}

(merealisasikan Sang Diri, Àtman yang tidak lain adalah percikan Tuhan Yang Maha Esa untuk mewujudkan kesejahtraan lahir dan kebahagian bathin (Mahadevan, 1984: 297).

Mewujudkan Jagadhita (kesejahtraan lahiriah) dan Mokûa (kebahagian yang sejati) adalah tujuan Hindu Dharma dan juga sekaligus pula tujuan hidup manusia.

Sedangkan yang menjadi tujuan Agama Hindu yang dirumuskan dalam kalimat: mokûàrthaý jagadhitàya iti dharmaá, yang maknanya melalui ajaran agama untuk mencapai jagadhita dan mokûa. Ajaran Agama Hindu bagaikan aliran sungai mengaliri berbagai budaya dan peradaban umat manusia, sejak diturunkan oleh-Nya di lembah sungai Sindhu hingga ke Indonesia mulai ndari kalimantan sampai Jawa dan Bali, agama ini menyuburkan lembah-lembah kehidupan, peradaban dan budaya umat manusia 
yang dilalui itu. Agama Hindu menjadi jiwa dari segala aktivitas pemeluknya serta peradaban dan budaya yang mereka anut. Menyatunya antara agama dan budaya, seperti jalinan benang tenun (kain endek Bali), yang menyatu sedemikian rupa dengan keindahannya yang mempesona. Di setiap wilayah yang dialiri oleh ajaran agama Hindu terjadi sinergi yang mempelihatkan identitas budayanya masing-masing, oleh karena itu akan tampak dalam àcàra Agama Hindu di masingmasing daerah, baik di India (tampak berbeda pelaksananan Agama Hindu di India Utara, Selatan, Barat, dan lain-lain karena faktor budaya pendukung agama tersebut), demikian pula di Indonesia, tampak perbedaan antara Agama Hindu yang dipeluk oleh warga Dayak Kaharingan, Hindu yang dipeluk oleh masyarakat Jawa dan sebagainya yang semuanya memiliki identitas budayanya masing-masing yang memberi warna budaya agama yang berbeda-beda.

\section{Keberadaan Bali pada Masa Prasejarah}

Bisa dikatakan bahwa Pulau Bali sebagai sebuah pulau kecil di hamparan katulistiwa Nusantara sejak masa prasejarah ikut serta dalam pertumbuhan budaya yang menjadi akar dari perkembangan kebudayaan nasional. Penelitian arkeologi yang selama ini dilakukan di Bali telah berhasil mengungkapkan awal hubungan daerah ini dengan India. Di situs Sembiran telah ditemukan puluhan fragmen gerabah India dengan pola hias rolet, dua buah fragmen tepian gerabah Arikamedu (India) tipe 10, dua buah tepian gerabah tepian Arikamedu tipe 18, sebuah gerabah Arikamedu tipe 141, dan sebuah batu bertulis dengan huruf Kharoshti atau Brahmi. Selain itu, ratusan pecahan gerabah yang dipoles dengan warna hitam kemungkinan juga berasal dari India karena mempunyai kandungan kimiawi dan mineral yang sama dengan gerabah berpola hias rolet tersebut. Perlu dicatat bahwa situs Sembiran dan Pacung di Bali Utara telah menghasilkan temuan gerabah India terbanyak sampai saat ini di Asia Tenggara.
Kronologi gerabah India di Sembiran mungkin berasal dari awal abad Masehi atau sekitar 2.000 tahun yang lalu (Ardika, 1997:62).

Pada masa bercocok tanam, dengan memperhatikan tipologi tinggalan beliung persegi di Bali, maka dapat dikatakan bahwa Bali pada masa itu telah mempunyai hubungan budaya yang luas dengan daerah lainnya di kepulauan Indonesia maupun di Asia Tenggara (di antaranya Malaysia, Burma, Kamboja, Thailand, Laos, dan bahkan dengan China dan Formosa). Hubungan yang demikian luas terjadi akibat adanya migrasi yang disebabkan oleh pencarian daerah yang lebih subur untuk kepentingan perladangan. Hal ini ditunjang oleh kamajuan teknologi alat-alat batu dengan beberapa macam tipologi yang dapat dipergunakan dalam pekerjaan khusus seperti pembuatan perahu sebagai alat transportasi laut dalam penyeberangan dari pulau ke pulau lain di kawasan Asia Tenggara (Suastika, 1997:38).

Sejalan dengan penelitian Suastika di atas, kini kepemilikan tanah di Desa Catur, Kintamani, Bangli lebih banyak dimiliki oleh etnis China yang memang mereka diduga telah datang ke Bali pada masa pertama kalinya terjadi hubungan antara Bali dengan China. Di Desa Catur, hingga kini diwarisi adanya pemujaan versi China yang di tempatkan di komplek Pura Desa di desa tersebut. Oleh umat Hindu setempat disebut sebagai tempat memuja Ratu Subandar. Hal yang sama dapat dijumpai di Pura Balingkang, Pura Ulundanu Batur, Kintamani, dan Pura Penataran Agung Besakih. Rupanya sejak zaman prasejarah Bali masyarakat Bali telah bersinergi dengan etnis luar (khususnya China).

Demikian pula pada masa perundagian. Masa perundagian adalah puncak segala kemajuan yang berhasil dicapai yakni merupakan perkembangan lebih lanjut dari masa bercocok tanam. Penduduk yang hidup bergabung dalam suatu desa, sudah berhasil mencapai suatu taraf yang baik dengan penguasaan teknologi yang tinggi seperti teknik pembuatan gerabah, kepandaian menuang 
perunggu. Masa perundagian telah menghasilkan kebudayaan Indonesia asli yang bernilai tinggi karena dijiwai oleh konsepsi alam pikiran yang hidup di dalam masyarakat pada waktu itu (Putra, 1987:50).

Kerajinan menuang benda-benda perunggu yang dibentuk menjadi bermacam-macam benda yang diinginkan, dapat disebutkan sebuah di antaranya yang ditemukan di Bali yang kini disimpan di Pura Penataran Sasih Pejeng, Gianyar yakni oleh masyarakat dinamakan "Bulan Pejeng" atau Nekara. Pembuatan Nekara ini dengan cara cire perdue atau cetakan hilang. Namun, yang perlu diperhatikan di sini adalah fungsi benda tersebut sebagai benda upacara keagamaan seperti upacara untuk mohon hujan, di samping ditemukannya hiasan kodok pada bagian bidang pukulnya dan juga sebagai genderang perang (Putra, 1987:51, Ardana, 1982: 50).

Selanjutnya pada masa perundagian, keberadaan seni pahat sudah berkembang dengan baik, terbukti dari pola hias kedok muka pada tonjolan beberapa sarkofagus serta arca-arca sederhana dari beberapa desa di Bali. Kemungkinan besar bahwa seni pahat dari masa perundagian inilah selanjutnya menjadi dasar bagi perkembangan seni pahat di Bali setelah Agama Hindu sampai di daerah ini (Darsana, 1997: 25). Sejalan dengan pandangan tersebut maka kepercayaan dan budaya pada masa prasejarah Bali merupakan landasan masuk dan berkembangnya Agama Hindu dan pertumbuhan kebudayaan Bali.

\section{E. Perkembangan Agama Hindu dan Buddha di Bali}

Tentang sejarah perkembangan agama Hindu di Bali, seperti diungkapkan oleh Swellengrebel (1960:17) sumber utamanya adalah prasastiprasasti yang dikeluarkan oleh para raja yang banyak jumlahnya baik yang tertulis pada batu maupun pada logam (tembaga). Prasasti-prasasti itu menceritakan para raja yang memerintah dan para menterinya, hubungannya dengan administrasi pemerintahan pusat dan orang-orang di desa-desa, peraturan di bidang keagamaan, aturan yang berhubungan dengan pengairan, perpajakan, dan sebagainya. Sumber lainnya adalah peninggalan purbakala, arca-arca dan artifakartifak. Berdasarkan ungkapan Swellengrebel di atas maka kehidupan keagamaan di Bali dapat dikaji melalui sumber-sumber tersebut di atas.

Hubungan Jawa dan Bali serta Nusantara dengan India di masa yang silam dapat diketahui dari kitab Ràmàyaóa karya Mahàrûi Vàlmìki, pada Kiûkindhakàóða (XL.30) menyebutkan nama Javadvìpa dan Saptaràjya, yang menurut Nabin Chandra Das (Widnya, 2001) Saptaràjya adalah tujuh tempat, yaitu Suvaróadvìpa (Sumatra), Kalimantan (Borneo), Sulawesi (Celebes), Irian Jaya (West New Guinea), Bali, Java, dan Malaya (Misra,1989: VI).

Hubungan antara India dengan Bali diungkapkan pula oleh Sarkar (Phalgunadi, 1991:33) termuat dalam kitab Båhatsaýhità dan Kathàsaritsàgara yang membuktikan sudah adanya kontak antara Bali dengan India dalam bidang perdagangan dan agama. Kedua buku di atas menyebutkan nama Bali sebagai Nàrikeladvipa. Sedangkan Pulau jawa disebut sebagai Jawa Dwipa. Menurut Damais yang dimaksud dengan Bhùmi Nàrikela adalah Pulau Bali yang menurut anggapannnya dapat dibuktikan dari sejumlah prasasti yang ditemukan di pulau ini. Banyak prasasti Bali yang menyebutkan Bali sebagai pulau kelapa. Prasasti Poh (tahun 905 Masehi) menyebutkan "vanua ri rùmakûan riò nyù" yang berarti pulau kelapa. Weber (1974: 202, 213) menyatakan Båhatsaýhità ditulis oleh Varamihira pada abad ke-5 atau ke-6 Masehi dan Kathàsaritsàgara ditulis oleh Somadeva pada abad ke-11 Masehi. Di dalam kitab Mañjuúrì Mùlakalpa secara tegas disebutkan nama Pulau Bali. Kitab ini diduga ditulis pada abad ke-7 Masehi (Widnya, 2001: 5) yang menunjukkan bahwa saat itu telah terjadi hubungan antara Bali dengan India.

Agama Hindu dan Buddha dikenal sebagai 
agama yang berasal dari sumber yang sama. Tinggalan prasasti dan arkeologi menunjukkan kedua agama ini hampir bersamaan tiba di Bali. Berdasarkan fragmen prasasti yang ditemukan di Pejeng, Gianyar, Agama Hindu sekta Saiva (Saivapaksa) diduga berkembang pada abad ke-8 Masehi. Fragmen prasasti ini ditulis memakai bahasa Sanskerta dan bila dibandingkan dengan stempel tanah liat yang berisi mantram agama Buddha yang disebut dengan ye-te mantra..... rupanya sezaman sehingga diduga berasal dari tahun 778 Masehi. Pada baris pertama dari prasasti tersebut tertulis: "Sivas.....ddh..... yang tidak mungkin berarti Sivasiddhanta (Ardana, 1982:20).

Data lainnya yang juga dapat menunjukkan sekta Saiva berkembang di Bali pada abad ke-8 Masehi adalah peninggalan purbakala, yakni berupa sebuah arca yang disebut arca Siva yang ditemukan pada sebuah pura bernama Putra Bhattara Desa di Desa Bedahulu (Sttuterheim, 1935:35). Arca ini berasal dari periode HinduBalinese Art, yakni dari abad ke-8 Masehi, pada saat yang bersamaan juga ditemukan arca Siva pada beberapa candi di kompleks Candi Dieng, Jawa Tengah (Kempers, 1959: 31). Data yang lebih autentik adalah data prasasti Sukawana A I yang berasal dari tahun 882 Masehi, yakni menyebutkan tiga tokoh agama, yaitu: bhiksu (pandita Buddha) Siva Kangsita, Siva Nirmala, dan Sivaprajña yang membangun pertapaan di puncak gunung Cintamani (Goris, I, 1954: 53). Di sini tidak dijelaskan agama yang dipeluk oleh ketiga pandita itu. Oleh karena ada kata bhiksu yang menunjukkan pandita Buddha dan nama Siva atau barangkali kedua agama itu disatukan (Sivabuddha) seperti pada masa pemerintahan Raja Udayana, karena sejak abad ke-10 Masehi kedua agama itu, yakni Siva dan Buddha menjadi agama negara (agama resmi)(Ardana, 1982: 21).

Menurut Goris (1960: 98), kedatangan Agama Hindu di Bali dalam dua bentuk, yakni dalam bentuk agama yang dibawa oleh para pandita (priestly religion) dan dalam bentuk kepustakaan (literature), khususnya dalam bentuk epik besar. Dalam epik besar ini, tidak semuanya sekta Saivasiddhanta, tetapi dapat diketahui dan diakui adanya tiga Dewa Brahma, Siva dan Visnu meskipun dalam epik itu ada yang spesifik, yaitu penekanan kepada Sivaistik dan Visnuistik. Dari kepustakaan tersebut diketahui akar dari hukumhukum dan orang Bali mengetahui ajaran Agama Hindu. Dalam epik Agama Hindu ditemukan banyak Dewa (Brahma dengan Saktinya Sarasvati, Siva dengan Durga, Visnu dengan Sri dan juga Ganesa, Dewa-Dewa yang populer dalam epik), banyak raksasa, dan roh-roh jahat. Di samping itu, terdapat penjelasan tentang persembahan, tempattempat pemujaan, dan kalender untuk menentukan waktu penyelenggaraan upacara. Selain itu, juga terdapat upacara-upacara untuk keperluan rumah tangga, upacara pembakaran jenasah (kremasi) bagi orang yang meninggal, upacara siklus hidup dari sejak lahir sampai mati, arti upacara-upacara, dan juga persembahan yang besar. Dalam hal ini Agama Hindu banyak berhubungan dengan ajaran agama asli orang Bali, sehingga merupakan daya tarik bagi orang Bali untuk menjadi penganut Agama Hindu-Bali yang baik. Sebagaimana dinyatakan oleh Goris, seperti tersebut di atas, maka kedatangan Agama Hindu yang dibawa oleh para pandita sangat memungkinkan untuk mendapat dukungan sepenuhnya dari raja-raja Bali yang berkuasa pada masa yang silam. Hal ini terbukti hingga kini masih tampak peranan pandita istana (purohita atau bhagawanta) sangat menentukan dalam kaitannya dengan upacara Yajna yang dilakukan oleh pihak kerajaan. Demikian pula dalam pengembangan susastra Hindu, peranan raja tidak kalah pentingnya. Perkembangan susastra Hindu di Bali, baik dengan media bahasa Jawa Kuna dan Tengahan maupun sastra Bali hingga kini masih berlangsung.

Adanya penelitiannya terhadap 4 raja yang berkuasa pada masa Bali Kuna, Semadi Astra (1997:280) menemukan ada 16 orang pemuka agama Siva dan 12 orang pemuka agama Buddha, sebagai berikut. 


\begin{tabular}{|c|c|c|c|}
\hline \multicolumn{2}{|c|}{$\frac{\text { PEMUKA AGAMA }}{\text { SIVA }}$} & \multicolumn{2}{|r|}{$\begin{array}{l}\text { PEMUKA AGAMA } \\
\text { BUDDHA }\end{array}$} \\
\hline 1. & $\begin{array}{l}\text { M p u k i n g } \\
\text { Dharmahanyar }\end{array}$ & 1. & Mpukwing Kutihanyar \\
\hline 2 . & $\begin{array}{l}\text { Mpukwing Hyang } \\
\text { Padang }\end{array}$ & 2. & Mpukwing Canggini \\
\hline 3. & Mpukwing Binor & 3. & 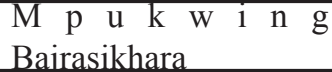 \\
\hline 4. & $\begin{array}{l}\text { M p u k w i n g } \\
\text { M p u k w i n g } \\
\text { Lokeswara } \\
\end{array}$ & 4. & Mpukwing Kadhiran \\
\hline 5. & $\begin{array}{l}\text { Mpukwing Banyu } \\
\text { Garuda }\end{array}$ & 5. & $\begin{array}{l}\text { M p u k w i n } \mathrm{g} \\
\text { Dharmaryya }\end{array}$ \\
\hline 6. & $\begin{array}{l}\text { M p u k w i n g } \\
\text { Makarun }\end{array}$ & 6. & Mpukwing Waranasi \\
\hline 7. & $\begin{array}{l}\text { Mpukwing } \\
\text { Antakunyarapada }\end{array}$ & 7. & 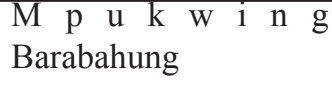 \\
\hline 8. & $\begin{array}{l}\text { Mpukwing } \\
\text { Udayalaya }\end{array}$ & 8. & Mpukwing Karana \\
\hline 9. & Mpukwing Kanya & 9. & 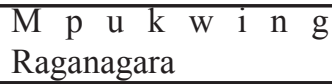 \\
\hline 10. & $\begin{array}{l}\text { M p u k w i n g } \\
\text { Kusumahajika }\end{array}$ & 10. & $\begin{array}{l}\text { M p u k w i } \\
\text { Purwanagara }\end{array}$ \\
\hline 11. & $\begin{array}{l}\text { M p u k w i g } \\
\text { K u s u ma d a n t a } \\
\text { (Puspadanta) }\end{array}$ & 11. & Mpukwing Nalnyja \\
\hline 12. & $\begin{array}{l}\text { M p u k w i n g } \\
\text { Kunjarapada }\end{array}$ & 12. & $\begin{array}{l}\text { Samgat } \\
\text { Mangirengngireng }\end{array}$ \\
\hline 13. & $\begin{array}{l}\text { M p u k w i n g } \\
\text { Pasabhan }\end{array}$ & & \\
\hline 14. & $\begin{array}{l}\text { M p u k w i n g } \\
\text { Sikharadwara }\end{array}$ & & \\
\hline 15. & $\begin{array}{l}\text { Mpukwing Hyang } \\
\text { karampas }\end{array}$ & & \\
\hline 16. & $\begin{array}{ll}\text { Samgat } & \text { Juru } \\
\text { Wadwa } & \\
\end{array}$ & & \\
\hline
\end{tabular}

Berdasarkan jumlah pemuka agama yang tersebut dalam jabatan pemerintahan empat raja pada zaman Bali Kuna di atas, dapat dinyatakan bahwa pemeluk Agama Hindu lebih banyak dibandingkan dengan agama Buddha.

Mengenai bangunan suci terkait dengan kedua agama di atas, sumber prasasti hanya menyebut beberapa istilah, seperti satra, patapan, hyang, vihara, sima, sala, kaklungan, pendem, kamulan, meru, dan sebagainya. Di antara nama-nama tersebut, wihara jelas merupakan pesanggrahan bagi para pendeta Buddha, hyang singkatan dari istilah kahyangan yang berarti tempat suci. Sampai sekarang di Bali tiga buah pura di tiap-tiap desa pakraman (desa adat) disebut
Kahyangan Tiga, yaitu Pura Desa, Puseh, dan Dalem. Patapan merupakan tempat untuk bertapa. Sima merupakan daerah perdikan yang tugasnya memelihara bangunan suci yang ada di daerah itu. Kamulan rupa-rupanya masih tertinggal menjadi sanggah kamulan di Bali yang sekarang berfungsi sebagai tempat penghormatan roh suci leluhur. Meru merupakan bangunan suci berbentuk atap tumpang terbuat dari ijuk.

Akhirnya perlu ditegaskan kembali bahwa pengaruh Budaya Jawa sangat besardi Bali sejakibu Airlangga (Mahendradattagunapriyadharmapatni) sebagai raja yang amat berkuasa di Bali. Prasastiprasasti yang diterbitkan sebelumnya berbahasa Bali Kuno yang bercampur dengan bahasa Jawa Kuno, maka sejak tahun 1.022 semua prasasti murni menggunakan bahasa Jawa Kuno (Satyawati, 1978:44). Dalam bidang susastra sejak pengaruh Hindu masuk ke Bali, pada mulanya tampak pengaruh bahasa Sanskerta dan Bali kuno, namun perkembangan berikutnya pengaruh bahasa Jawa Kuno atau Kawi sangat mendominasi, seperti dinyatakan oleh T. Goudriaan (1980: 31) berikut.

In Bali, the sign of a Hinduised culture are found from 8th century onwards. One might rightly speak of an independent Hindu-Balinese culture besides the Hindu-Javanese one of Java; some facts is that the oldest Balinese inscriptions are written in Sanskrit and Old Balinese. From about the year 1000 onwards. Old Balinese is gradually pushed aside by Old Javanese; a sign of the increasing dominance of Java over the much smaller Bali. In the 14th century, Bali even became a centre for the study of old Javanese literatuer. The influx of Islam, which did not touch Bali, completed the role of this island as a presever of HinduJavanese culture and literary treatures, a role which it has maintained up to these days.

Tentang susastra Jawa Kuno atau Kawi yang mendominasi susastra Hindu di Bali, baik dalam genre parwa, kakawin, dan kidung telah dikaji secara komprehensif oleh P.J. Zoetmulder 
dalam karya monumentalnya Kalangwan. A Survey of Old Javanese Literature (1974) dan telah diterjemahkan ke dalam bahasa Indonesia oleh Dick Hartoko SJ. Kalangwan, Sastra Jawa Kuno Selayang Pandang (1983). Demikian pula hal yang sama dilakukan oleh Rajendra Mishra dalam Sejarah Kesusastraan Sanskerta (1989: 84) yang menjelaskan secara gamblang sumber utama susastra Sanskerta seperti Àrûa Kàvya (Kàbya) yakni Ràmàyaóa dan Mahàbharata, susastra puisi (Mahàkàvya dan Khaóðakàvya), prosa (Kathà dan Àkhyàyikà), dan drama (Daúarùpaka) yang disadur atau disusun dalam bentuk yang lain dan baru oleh Rakawi Susastra Jawa Kuno baik dalam genre parwa, kakawin, dan kidung yang diwarisi di Bali.

Selain dominasi susastra Jawa Kuno seperti tersebut di atas, I Made Suastika menyatakan bahwa pada abad ke-18 (zaman Kerajaan Klungkung) karya sastra Jawa Kuno dan Pertengahan digubah dalam genre baru yang disebut parikan atau gaguritan (1995:30), maka sekitar abad ke-17 sampai dengan abad ke-19 teks-teks baik berbentuk kidung atau gaguritan sudah sangat populer di antaranya karya sastra berupa Kidung Panji Amalatrasmi, Gaguritan Bhimasvarga, Kidung Bagus Diarsa dan lain-lain disusun oleh para sastrawan pada zaman tersebut yang memberi pemahaman tentang Agama Hindu bagi masyarakat Bali. Aktivitas memahami susastra Jawa Kuno hingga saat ini masih dilestarikan melalui Dharmagita atau PesantianPesantian yang ada hampir di seluruh Desa Pakraman di Bali. Di Bali yang dimaksud dengan susastra Bali tidak lain adalah sebagian besar susastra Jawa Kuno dan sebagian kecil susastra berbahasa Bali, menunjukkan bahwa budaya Bali menyerap budaya Jawa Kuno yang sumbernya adalah budaya India.

Berdasarkan tampilan dari seni arca, maka terlihat karakter arca dalam periode Hindu Bali (periode pertama Hindu masuk ke Bali) terlihat lemahlembut,kegemuk-gemukan, bersikaptenang, mata setengah terbuka, pandangan mengarah ke ujung hidung. Ciri-ciri arca semacam ini dapat dijumpai dalam stupika-stupika tanah liat yang banyak didapatkan di sekitar desa Pejeng, Tatiapi, dan Blahbatuh tetapi arca ini bersifat Buddhist. Untuk arca Hindu dapat dicontohkan arca Siwa yang terdapat di Pura Putra Bhatara Desa Bedulu. Kecuali arca Siwa tersebut, arca Hindu lainnya, belum ditemukan tinggalannya. Konteksnya dengan daerah lain, tak dapat dipungkiri bahwa seni arca di Bali saat itu mendapat pengaruh seni klasik Jawa Tengah. Ciri-ciri kelemahlembutan, kegemukan, dan lain sebagainya seperti tersebut di atas adalah ciri-ciri arca klasik Jawa Tengah. Akan tetapi arca yang berciri demikian bukan saja didapatkan di Jawa dan Bali, tetapi juga di Kamboja, Thailand, Bhirma, dan Malaysia. Karena itulah maka arca-arca masa klasik Jawa Tengah disebut memiliki "Gaya Intemasional", dan pusat persebarannya diduga di Nalanda (Redig, 1997: 172). Berdasarkan uraian tersebut di atas, awal mulanya pengaruh Hindu di Bali dari seni arca masih menampakkan gaya internasional atau gaya asli India. Dalam perkembangan berikutnya, utamanya bentuk arca perwujudan tampak kaku, seperti pula halnya di Jawa Timur. Dalam seni ukir yang diwarisi dewasa ini, tampak pula pengaruh China, Arab, dan Belanda seperti patra (lukisan atau ukiran daun), di antaranya: Patra China, Patra Mesir, dan Patra Welanda. Dalam seni tari, tari-tarian yang terdapat pada masa Bali Kuno tampak hingga kini masih lestari, di antaranya adalah Partapukan yang kini dikenal dengan tari topeng, Abanwal yang dikenal dengan lawak. Demikian pula beberapa jenis gamelan masih berkelanjutan diwarisi kini di Bali.

\section{Akulturasi Budaya Jawa dan Budaya Bali}

Akulturasi merupakan perpaduan yang terjadi antara Budaya Jawa dan Budaya Bali hingga membentuk tradisi Bali yang kental dengan Nuansa adatnya daripada Agamanya. Agama Hindu di Bali sudah dibudidayakan menjadi kehidupan 
nyata sehingga menjadi adat dan Tradisi. Untuk mengetahui bagaimana kebudayaan Bali (masa prasejarah) mendapat pengaruh dari Agama Hindu (yang mengantarkan memasuki masa sejarah) kiranya dapat dilihat melalui kerangka tentang unsur-unsur kebudayaan seperti yang diajukan oleh C. Kluckhohn dalam karangannya Universal Categories of Culture (1953) seperti yang disetujui oleh Koentjaraningrat (1980: 217) yang terdiri dari: bahasa, sistem pengetahuan, organisasi sosial, sistem peralatan hidup dan teknologi, sistem mata pencaharian hidup, sistem religi, dan sistem kesenian. Pengaruh Agama Hindu terhadap 7 unsur kebudayaan Bali dapat dijelaskan sebagai berikut.

1) Bahasa. Seperti telah disebutkan di atas, bahwa Agama Hindu masuk ke Bali pada mulanya melalui media bahasa Sanskerta kemudian sejak pemerintahan Mahendradattagunapriyadharmapatni (permaisuri raja Dharmodayana Varmedeva), maka bahasa Jawa Kuno menggantikan media berbagai susastra Hindu dan hal ini tampak pengaruhnya terhadap bahasa Bali dewasa ini. Dalam mantra stuti masih menggunakan bahasa Sanskerta ${ }^{4}$.

2) Sistem pengetahuan. Melalui media bahasa Sanskerta dan Jawa Kuno masyarakat Bali memiliki berbagai sistem pengetahuan yang bersumber dari Agama Hindu dan budaya India, antara lain sistem pengobatan (ausadha), pembangunan rumah (hastakosalakosali dan hastabhumi) dan lain-lain.

3) Organisasi sosial. Pada prasasti-prasasti Bali Kuno sebelumnya disebut adanya sistem pemerintahan serta adanya lembaga kerajaan yang disebut panglapuan, paramaksa, samohanda, dan senapati di panglapuan. Sejak tahun 1001 Masehi, lembaga tersebut dinamakan pakira-kira i jero makabehan yang anggotanya terdiri dari para senapati (panglima perang) dan para pandita Siva dan Buddha (Ardana, 1982:31), demikian pula sistem pemerintahan di pedesaan seperti adanya karaman, thani, dan dalam perkembangan selanjutnya di Bali dikenal adanya tipe desa kuno dengan sistem pemerintahnan Mauluapad dan sistem pemerintahan yang dipimpin oleh raja atau para Punggawa.

4) Sistem peralatan hidup. Di samping sistem yang peralatan hidup yang merupakan produk asli Bali, sejak zaman prasejarah sudah pula memakai peralatan yang berasal dari luar, misalnya dapat dilihat dari tinggalan gerabah Arikamedu dari India Selatan yang rupanya sudah berlangsung sejak awal abad Masehi.

5) Sistem mata pencaharian. Pada masa prasejarah hingga dewasa ini rupanya pertanian yang kemudian berkembang dalam arti luas termasuk perkebunan walaupun merupakan hal yang sangat universal, pengaruh Agama Hindu tampak dari semua sistem pencaharian itu dikaitkan dengan Agama Hindu, artinya dalam memenuhi kebutuhan hidup senantiasa dikaitkan dengan pemujaan kepada Tuhan Yang Maha Esa. Hal ini tampak hingga dewasa ini sistem pengairan yang sangat terkenal yakni Subak selalu dikaitkan dengan Agama Hindu, misalnya disetiap mata air dan di tempat pembagian air dibangun pura Ulunsui, Bedugul, dan sebagainya.

6) Sistem Religi. Ketika Agama Hindu masuk ke Bali, masyarakat Bali saat itu telah menganut kepercayaan kepada roh suci leluhur, adanya penguasa alam, dan gunung-gunung yang dianggap suci. Agama Hindu yang memiliki keyakinan (Sraddha) yang sama dengan kepercayaan setempat, yakni Pitrapuja (pemujaan kepada roh suci leluhur) mudah saja diterima oleh masyarakat Bali saat itu. Dan hal tersebut berlangsung hingga saat ini. Kedatangan Agama Hindu ke Bali tidak mengubah kepercayaan setempat tetapi memberikan pencerahan dengan lebih mengembangkan kepercayaan setempat. Pemujaan kepada penguasa tertinggi masyarakat Terunyan yakni $\mathrm{Da}$ Tonta berupa arca batu megalitik, dipermulia dengan menempatkan kata Bhattara pada nama sebelumnya dan kemudian disemayamkan pada bangunan Meru. Hal ini dapat diketahui antara lain dari prasasti Terunyan yang berasal dari 818 Saka (896 M), isinya tentang 
pemberian ijin kepada nanyakan pradhana dan bhiksu agar membangun sebuah kuil untuk Hyang Api di desa Banua Bharu. Prasasti lainnya berasal dari tahun 813 Saka (891 M) isinya tentang pemberian ijin kepada penduduk desa Turuñan untuk membangun kuil bagi Bhatara Da Tonta. Oleh karena itu mereka dibebaskan dari beberapa jenis pajak, tetapi mereka ini dikenakan sumbangan untuk kuil tadi. Beberapa jenis pajak harus dibayar setiap bulan Caitra dan Magha, pada hari kesembilan (mahanavami). Bila ada utusan raja datang menyembah (sembahyang) pada bulan Asuji, mereka harus diberi makanan dan sebagainya (Sartono, 1976:136). Dalam prasasti itu juga menyebutkan haywahaywan di magha mahanavami (Goris, 1954:56). Dalam bahasa Bali dewasa ini kata mahaywahaywa (dari kata mahayu-hayu) berarti merayakan. Haywahaywan di magha mahanavami berarti perayaan Magha Mahanavami. Di India Mahanavami identik dengan Dasara yakni hari pemujaan ditujukan kepada para leluhur (Dubois, 1981:569). Swami Sivananda (1991:8) mengidentikkan Dasara dengan Durgapuja yang dirayakan dua kali setahun, yakni Ramanavaratri atau Ramanavami pada bulan Caitra, dan Durganavaratri atau Durganavami pada bulan Asuji (SeptemberOktober). Perayaan ini disebut juga Wijaya Dasami atau Sraddha Wijaya Dasami (hari pemujaan kepada leluhur dan perayaan kemenangan selama sepuluh hari). Hari raya ini di Bali (dirayakan dua kali dalam setahun) dikenal dengan nama Galungan yang hakekatnya adalah Durgapuja atau Sraddha Vijaya Dasami (hari pemujaan kepada leluhur dan perayaan kemenangan selama sepuluh hari) yang dirayakan secara besar-besaran sejak Gunapriyadharmapatni di-dharmakan sebagai Durgamahisasuramardhini di pura Kedharma Kutri, Blahbatuh, Gianyar ${ }^{5}$.Beberapa hari raya Hindu di India dipribhumikan ke dalam bahasa lokal antara lain Ayudhapuja di Bali disebut Tumpek Landep, Pasupatipuja disebut Tumpek Uye, dan Sankarapuja disebut Tumpek Pengarah. Yatra disebut Melis, Makiyis, atau Melasti dan beberapa persembahan seperti puja disebut daksina, jajan dari beras berlobang di India selatan disebut Kalimaniarem, di Bali disebut Kaliadrem $^{6}$ dan sebagainya. Karena adanya persamaan dalam keyakinan dengan religi prasejarah, maka masyarakat Bali saat itu tidak kesulitan dalam memeluk Agama Hindu yang ajarannya telah terdokumentasi dalam bentuk tulisan atau dibawa oleh para pandita.

7) Sistem Kesenian. Sistem ini (kesenian Bali) walaupun tidak bisa dirunut asalnya secara pasti namun adanya pertunjukkan wayang kulit yang oleh Brandes disebut sebagai kesenian asli Indonesia, di Jawa hingga saat ini keberadaan Wayang Kulit masih juga eksis baik yang dipentaskan pada malam maupun siang hari (seperti wayang lemah), demikian pula pementasan cerita Ramayana, dan Bhimakumara seperti disebutkan dalam prasasti Jaha di Jawa Tengah bersumber kepada Ramayana dan Mahabharata yang di India disebut Ramalila dan Mahabharatalila atau Krishnalila.

Berdasarkan uraian tersebut maka masuknya perpaduan Budaya Jawa dan Budaya Bali yang membentuk Karakter Agama Hindu di Bali tidak merusak atau melenyapkan kepercayaan atau kebudayaan, dan bahkan dalam hal tertentu sangat menghargai kepercayaan dan tradisi budaya masyarakat Bali. Demikian antara lain pengaruh atau sinergi Agama Hindu terhadap berbagai aspek atau unsur-unsur kebudayaan Bali yang demikian rupa seperti sulit dibedakan antara Agama Hindu dan kebudayaan Bali.

Persamaan antara religi prasejarah Bali dengan Budaya Jawa dapat dilihat beberapa di antaranya melalui perbandingan berikut . 
1. Sebutan untuk Tuhan adalah Sang Embang/Sang Hyang Tuduh.

2. Dewa yang bersemayam di puncak Gunung Agung disebut To Langkir

3. Tempat yang dipandang suci adalah gunung, sungai, laut.

4. Percaya terhadap kekuatan alam yang disebut Hyang.

5. Percaya terhadap roh sucileluhur dengan perwatan jenasah dan roh suci dianggap bersemayam di puncak-puncak gunung. Membuat tiruan gunung berupa punden

6. berundak-undak, menhir dan tahta batu.

7. Tinggalan situs Gilimanuk ditemukan gigi manusia telah dipanggur.

8. Tinggalan sikap jenasah pada sarkopagus dalam posisi bayi dalam kandungan menunjukkan adanya kepercayaan akan kelahiran kembali.

9. Adanya orientasi arah yang dipandang suci yakni utara dan timur.

10. Adanya persembahan dan bekal kubur.
1. Sebutan untuk Tuhan adalah Sang Embang/Sang Hyang Tuduh.

2. Dewa yang bersemayam di puncak Gunung Agung disebut To Langkir

3. Tempat yang dipandang suci adalah gunung, sungai, laut.

4. Percaya terhadap kekuatan alam yang disebut Hyang.

5. Percaya terhadap roh suci leluhur dengan perwatan jenasah dan roh suci dianggap bersemayam di puncakpuncak gunung.

6. Membuat tiruan gunung berupa punden berundak-undak, menhir dan tahta batu.

7. Tinggalan situs Gilimanuk ditemukan gigi manusia telah dipanggur.

8. Tinggalan sikap jenasah pada sarkopagus dalam posisi bayi dalam kandungan menunjukkan adanya kepercayaan akan kelahiran kembali.

9. Adanya orientasi arah yang dipandang suci yakni utara dan timur.

10. Adanya persembahan dan bekal kubur.

\section{F.Simpulan}

Mengetahui Hakikat Budaya Jawa dalam kaitanya dengan perkembangan Hindu di Bali membentuk karakter Hindu Bali yang pada akhirnya menjadi Budaya Bali. Agama Hindu di Bali lebih terlihat pada Adat dan Tradisinya, hal ini diakibatkan adanya pembudiyaan Agama menjadi praktik kehidupan nyata. Sehingga keberadaan Agama Hindu tidak secara jelas terlihat dengan kitab Wedanya sebagai dasar pedomannya melainkan Lontar-Lontar yang dijadikan praktik dalam adat baik dalam ritual maupun nyastra sehingga tidak dijumpai ketika acara keagamaan memakai Weda sebagai bahan bacaan di Pura maupun dalam pedoman ritualnya. Hal ini menunjukkan pengaruh Budaya Jawa lebih kuat daripada pengaruh Budaya India yang menjadi Sumber Ajaran Hindu dengan Kitab Wedanya. 


\section{DAFTAR PUSTAKA}

Ardana, I Gusti Gede.1982. Sejarah Perkembangan Hinduisme. Denpasar: Tanpa Penerbit.

Ardika, I Wayan. 1997. 'Bali dalam Sentuhan Budaya Global' dalam Dinamika Kebudayaan Bali. Denpasar: Upada Sastra.

Ardika, I Wayan. 2005. 'Strategi Bali Mempertahankan Kearifan Lokal di Era Global' dalam Kompetisi Budaya dalam Globalisasi, Kusumanjali untuk Prof. Dr. Tjokorda Rai Sudharta. Denpasar: Fakultas Sastra Universitas Udayana dan Pustaka Larasan.

Chandrasekharendra Sarasvati, Sri Svami.1988. The Vedas. Bombay, India: Bharatiya Vidya Bhavan.

Darsana, I Gusti Putu.1997. Akar Kebudayaan Bali. Denpasar: Upada Sastra.

Darori Amin, 2000. Islam dan Kebudayaan Jawa. Yogyakarta: Gama Media.

Dayananda Sarasvati, Svami. 1984. An Introductio the the Vedas. New Delhi: Arya Pratinidhi Sabha.

Dubois, Abbe J.A.1981. Hindu Manners, Customs and Ceremonies. Delhi: Oxford University Press.

Ellsberg, Robert. 2004. Gandhi on Christianity. Yogyakarta: LKiS Pelangi Aksara.

Gambirananda, Swami. 1984. Brihadaranyaka Upanisad. Calcuta: Shri Ramakrishna Mission.

Geriya, I Wayan.2006. Bali dan Paradigma Kultural untuk Bangkit. Bali Post, 20 Februari 2006.

Goris, R.1954. Prasasti Bali, I-II. Bandung: NV Masa Baru.

Goris, R. 1960. “The Religious Character of the Village Community" dalam Bali Studies in Life, Thought, and Ritual, Ed. J.L. Swellerebel, The Hague and Bandung: W. Van Hoeve Ltd.

Goudriaan, T. 1980. Sanskrit Texts and Indian Religion in Bali, dalam Jurnal Vivekananda Kendra Patrika, Madras, India: February, 1980

Kellerman, Dana F.1976. The New Lexicon Webster International Dictionary of The English Language. United States of America: The English-Language Institute of America, Inc.

Koentjaraningrat.1980. Pengantar Ilmu Antropologi.Jakarta: Aksara Baru.
Khalil, ahmad, islam Jawa, Sufisme dalam Etika dan Tradisi Jawa, Malang: UIN Malang Press,2008

Magnis, Fraz suseno, Etika jawa: sebuah analisis falsafi tentang kebijaksanaan hidup jawa (Jakarta: Gramedia pustaka utama,1993)

Mahadevan, T.M.P. 1984. Outline of Hinduism. Bombay, India: Chetana.

Mani, Vettam.1989. Puranic Encyclopaedia. New Delhi: Motilal Banarsidass.

Mishra, Rajendra, 1989. Sejarah Kesusastraan Sanskerta. Denpasar: Publisher.

Phalgunadi, I Gusti Putu, 2005. "Bali Embraces Hinduism" dalam Kompetensi Budaya Dalam Globalisasi, Kusumanjali untuk Prof. Dr. Tjokorda Rai Sudharta, MA, Editor Darma Putra \& Windhu Sancaya, 2005, Denpasar: Fakultas Sastra Universitas Udayana dan Pustaka Larasan.

Putra, I Gusti Agung dkk. 1987. Sejarah Perkembangan Agama Hindu di Bali. Denpasar: Pemerintah Daerah Tingkat I Bali.

Radhakrishnan, S. 1989. Indian Philosophy. Bombay-New Delhi, India: Oxford University Press.

Redig, I Wayan.1997. Ciri-Ciri Ikonografis Beberapa Arca Hindu di Bali: Studi Banding Dahulu dan Sekarang dalam Dinamika Kebudayaan Bali. Editor: I Wayan Ardika dan I Made Sutaba. Denpasar: Upada Sastra.

Sartono Kartodirdjo dkk.1976. Sejarah Nasional Indonesia. II. Jakarta: Departemen Pendidikan dan Kebudayaan.

Satyawati Sulaiman, 1978. Consise Ancient History of Indonesia. Jakarta: The National Research Centre of Archeology.

Sivananda, Svami. 1988. All About Hinduism. Sivananda Nagar, Uttar Pradesh, India: Divine Life Society.

Suacana, I Wayan Gede. 2005. Diferensiasi Sosial dan Penguatan Toleransi dalam Masyarakat Multikultur, dalam Jurnal Kajian Budaya, Indonesia Journal of Cultural Studies. Nomor 3 Volume 2, 2 Januari 2005.

Suastika, I Made. 1995. Calon Arang dalam Tradisi Bali: Suntingan Teks, Terjemahan, dan Proses Pem-Bali-an: Disertasi Universitas Gadjah Mada Yogyakarta. 